\title{
Translation, Adaptation and Validation of the European Portuguese Version of the NMS-Quest for Parkinson's Disease
}

\section{Tradução, Adaptação e Validação da Versão Portuguesa do Questionário de Sintomas Não-Motores para a Doença de Parkinson}

\author{
Alexandra SILVA ${ }^{1}$, Tiago PEDRO ${ }^{2}$, Fradique MOREIRA $\triangle^{1}$ \\ Acta Med Port 2021 Jan;34(1):6-11 $\cdot$ https://doi.org/10.20344/amp.13160
}

\section{ABSTRACT}

Introduction: Non-motor symptoms are underrecognized features of Parkinson's disease that impair quality of life and increase mortality. In this study, we aim to translate, adapt and validate the European Portuguese version of the "Non-Motor Symptoms Questionnaire", which has proven to be a valid and reliable measurement tool of non-motor symptoms in other languages.

Material and Methods: Acceptability was evaluated regarding the range of values, ceiling and floor effects. Reliability was measured in terms of internal consistency (Cronbach's alpha) and reproducibility (intra-class correlation coefficient). For criterion validity analysis, Movement Disorders Society - Unified Parkinson's Disease Part I domains' scores were compared to those of the "Non-Motor Symptoms Questionnaire". For convergent validity, correlations between the "Non-Motor Symptoms Questionnaire" and the Movement Disorders Society - Unified Parkinson's Disease Part III, Mini-Mental State Examination score, disease duration, and severity were obtained. Results: Seventy nine Parkinson's disease patients were recruited, with a mean age of $67.2 \pm 10.7$ years and a disease duration of $10.8 \pm 8.8$ years. The European Portuguese version of the "Non-Motor Symptoms Questionnaire" total score was free of significant ceiling and floor effects. With the exception of the cardiovascular domain, adequate overall internal consistency was achieved. The questionnaire domains and the corresponding Movement Disorders Society - Unified Parkinson's Disease Part I dimensions were significantly correlated, although the total questionnaire score was modestly correlated with disease duration and severity, motor and non-motor symptoms severity and cognitive dysfunction.

Discussion: This is the first study to translate, adapt and validate a widely used screening instrument of non-motor symptoms of European Portuguese speaking Parkinson's disease patients.

Conclusion: The European Portuguese version of "Non-Motor Symptoms Questionnaire" is a valid and reliable tool for screening nonmotor symptoms in patients with Parkinson's disease.

Keywords: Neurologic Examination; Parkinson Disease/diagnosis; Portugal; Psychometrics; Reproducibility of Results; Surveys and Questionnaires; Translating

\section{RESUMO}

Introdução: Os sintomas não-motores da doença de Parkinson são ainda pouco reconhecidos, apesar do impacto na qualidade de vida e na mortalidade. O Questionário de Sintomas Não-Motores é uma ferramenta válida e confiável para avaliação dos sintomas não-motores noutros idiomas. O objetivo deste estudo é traduzir, adaptar e validar a versão portuguesa do Questionário de Sintomas Não-Motores.

Material e Métodos: A aceitabilidade foi avaliada através da amplitude de valores, efeito de teto e de chão. A fiabilidade foi medida em termos de consistência interna (alfa de Cronbach) e de reprodutibilidade (coeficiente de correlação intraclasse). Para a validade de critério, o Questionário de Sintomas Não-Motores foi comparado com a escala Movement Disorders Society - Unified Parkinson's Disease Parte I. A validade convergente foi avaliada através de correlações entre o Questionário de Sintomas Não-Motores, Movement Disorders Society - Unified Parkinson's Disease Parte III, pontuação na Mini-Mental State Examination, duração de doença e severidade de doença.

Resultados: Recrutámos 79 doentes com doença de Parkinson, com idade média de 67,2 \pm 10,7 anos e uma duração média de doença de 10,8 \pm 8,8 anos. A versão portuguesa do Questionário de Sintomas Não-Motores revelou propriedades psicométricas adequadas. O questionário (alfa de Cronbach $=0,862$ ) e os seus domínios demonstraram uma consistência interna adequada, com exceção do domínio cardiovascular (alfa de Cronbach = 0,173). Em termos de validade, verificaram-se correlações fortes entre a maioria dos domínios do Questionário de Sintomas Não-Motores e as dimensões correspondentes da Movement Disorders Society - Unified Parkinson's Disease Parte I. A pontuação total do Questionário de Sintomas Não-Motores mostrou correlações moderadas com a duração e severidade da doença, severidade dos sintomas motores, não-motores e disfunção cognitiva.

Discussão: Este é o primeiro estudo a traduzir, adaptar e validar uma ferramenta frequentemente utilizada para rastreio de sintomas não motores na doença de Parkinson.

Conclusão: A versão portuguesa do Questionário de Sintomas Não-Motores é uma ferramenta válida e confiável para avaliar os sintomas não-motores nos doentes com doença de Parkinson.

Palavras-chave: Doença de Parkinson/diagnóstico; Exame Neurológico; Inquéritos e Questionários; Portugal; Psicometria; Reprodutibilidade dos Testes; Tradução

\footnotetext{
1. Neurology Department. Centro Hospitalar e Universitário de Coimbra. Coimbra. Portugal.

2. Neurology Department. Faculdade de Medicina. Universidade de Coimbra. Coimbra. Portugal.

$\triangle$ Autor correspondente: Fradique Moreira. fradiquevam@hotmail.com

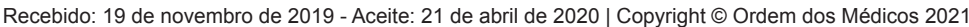




\section{INTRODUCTION}

Parkinson's disease (PD) is a multisystem neurodegenerative disorder, commonly known by its cardinal motor features, such as bradykinesia, rigidity, and tremor. ${ }^{1}$ However, non-motor symptoms (NMS) including cognitive impairment, psychiatric, sleep, autonomic, gastrointestinal and sensory disturbances are found in the majority of PD patients ${ }^{2}$ and may precede the development of motor dysfunction..$^{1,3}$ NMS may have a greater impact on quality of life than motor symptoms, with several studies showing a negative outcome on the quality of life of patients with PD.4-7 Its severity has been recently shown to increase the risk of mortality among Portuguese PD patients. ${ }^{8}$ Despite being highly prevalent and potentially treatable, they are still insufficiently diagnosed and remain underrecognized in over $50 \%$ of the consultations performed by neurologists. ${ }^{9}$ Frequently used scales and scores do not adequately detect these non-motor symptoms, ${ }^{10}$ which make the development of an easy, fast and reliable NMS screening tool, imperative.

The NMS Questionnaire (NMS-Quest) is a self-completed patient questionnaire comprising 30 qualitative questions that assess the presence of all important non-motor symptoms through a dichotomic "yes" or "no" answer. The original English version was designed in 2006 to be a quick screening tool used by neurologists to perceive the patient's NMS burden during the previous month. The questionnaire takes from 10 to 15 minutes to complete after which the items can be combined into nine domains: gastrointestinal (8 items), urinary tract (2 items), sexual function (2 items), cardiovascular (2 items), apathy/attention/memory (3 items), hallucinations/delusions (2 items), depression/ anxiety/anhedonia ( 2 items), sleep/fatigue ( 5 items), pain (1 item) and miscellaneous (3 items).

Since there is no Portuguese version of the NMS-Quest, self-translated versions are often used in clinical practice. Our study aims to translate, adapt and validate the original NMS-Quest version to the European Portuguese language, following international guidelines for adaptation of questionnaires.

\section{MATERIAL AND METHODS}

\section{Participants and selection}

Patients diagnosed according to the United Kingdom Parkinson's Disease Society Brain Bank Criteria ${ }^{11}$ were consecutively recruited from our Movement Disorders Unit between June and October 2019. Cognitive dysfunction was screened using Mini-Mental State Evaluation (MMSE) and the following cut-offs were applied: $\leq 15$ if illiterate, $\leq$ 22 if $1-11$ years of education and $\leq 27$ if more than 11 years. ${ }^{12}$ Cognitive and debilitating deficits (e.g. blindness) were established as exclusion criteria. Sociodemographic data were collected regarding gender, age, and literacy.

Clinical aspects including disease duration, Hoehn and Yahr (H\&Y) scale, Movement Disorders Society-Unified Parkinson's Disease Rating Scale (MDS-UPDRS) - Part I and III, and MMSE scale were evaluated by the same neurologist. Each questionnaire was applied in a private room and checked for missing answers. Informed consent was obtained from all participants and our protocol was approved by the local Ethics Committee (reference number CHUC-116-19).

\section{NMS-Quest translation and adaptation}

The translation, adaptation and validation process followed the instructions provided by the Movement Disorders Society upon request and the study was conducted according to the Good Clinical Practice guidelines. ${ }^{13}$ The original English version of NMS-Quest was first translated into Portuguese by two independent bilingual experts and a consensual version was obtained after grammatical and semantic comparison. Then, the consensus version was back-translated into English by another bilingual speaker unaware of the original scale to rule out semantic discrepancies between the original and the translated version of the scale. The Portuguese version of NMS-Quest was reviewed by an experienced clinician and highly knowledgeable in Movement Disorders to test for content validity, and it was applied in a pretesting trial with 10 PD patients in order to assess cultural differences and sensitivities. A final Portuguese version of NMS-Quest was created afterwards and is presented in Appendix 1 (see Appendix 1: https:// www.actamedicaportuguesa.com/revista/index.php/amp/ article/view/13160/Appendix_01.pdf).

\section{Data analysis}

Descriptive statistics were used for sample demographic characterization and questionnaire results. Content validity was achieved through expert review. For analysis purposes, the items were grouped into nine domains following the recommendations of the Movement Disorders Society: digestive (items 1 to 7 ), urinary (items 8 and 9), apathy/ attention/memory (items 12,13, and 15), hallucinations/ delusions (items 14 and 30), depression/anxiety (items 16 and 17), sexual function (items 18 and 19), cardiovascular (items 20 and 21), sleep disorders (items 22 to 26), and miscellany (items 10, 11, 27, 28, and 29). One point was scored in case of a positive answer for each question and zero points in case of a negative response. The final score for each domain was then calculated and patients with at least one positive answer were considered to have corresponding symptoms to that domain.

For convergent validity, correlations between NMSQuest domains and MDS-UPDRS Part III, MMSE scores, and disease duration and severity were performed using the Spearman correlation coefficient $(\rho)$. Correlations were considered very strong when a coefficient was greater than 0.90 , strong if between 0.70 and 0.90 , moderate if between 0.50 and 0.70 , weak if between 0.30 and 0.50 and very weak if below $0.30 .{ }^{14}$ Criterion validity was analyzed by correlating NMS-Quest and MDS-UPDRS Part I domains scores using Spearman correlation coefficient $(\rho)$. Some MDS-UPDRS Part I items were grouped into a common dimension comparable to that in the NMS-Quest, although 
sexual function (NMS-Quest) and dopamine dysregulation syndrome (MDS-UPDRS Part I) were left without possible comparison. The acceptability was evaluated in terms of range of values, ceiling and floor effects. An effect $\leq 15 \%$ is considered acceptable. Internal consistency of each domain was tested using Cronbach's alpha and values $\geq 0.70$ were considered adequate indicators of reliability. The test-retest and intra-rater reliability were assessed using intra-class correlation (ICC) based on an absolute-agreement, 2-way mixed-effects model. A coefficient $\geq 0.70$ was deemed as acceptable. ${ }^{14}$

The statistical analysis was executed using IBM SPSS version 25 with a level of significance set at 0.05 .

\section{RESULTS}

A total of 79 PD patients were included, the majority of which were males $(57 \% ; n=45)$. The participants had a mean age of $67.2 \pm 10.7$ years (range $35-87$ ) and a mean disease duration of $10.8 \pm 8.8$ years. The mean $\mathrm{H} \& \mathrm{Y}$ stage was $2.3 \pm 0.6(3.8 \%, \mathrm{n}=3$ in stage $1 ; 67.1 \%, \mathrm{n}=53$ in stage $2 ; 25.3 \%, n=20$ in stage $3 ; 3.8 \%, n=3$ in stage 4 ). The MDS-UPDRS-Part III mean score for motor symptoms severity was $30.7 \pm 13.0$ and the MDS-UPDRS-Part I mean score for non-motor symptoms severity was $10.5 \pm 4.9$. The clinical and demographic features are shown in Table 1.

\section{Acceptability}

As shown in Table 2, gastrointestinal symptoms were the most common and were reported by $82.3 \%(n=65)$ of patients, followed by sleep disorders $(81.0 \% ; n=64)$. Hallucinations and/or delusions were present in $27.8 \%$ ( $n$ $=22$ ) of patients and were the least frequent. All domains showed a floor effect, with hallucinations/delusions being the most prominent $(72.2 \%)$. Apart from the digestive and miscellany domains, all others showed a ceiling effect, the highest $(68.4 \%)$ being presented by the depression/anxiety dimension. The NMS-Quest total score was free of significant ceiling $(2.5 \%)$ and floor $(1.3 \%)$ effects.
Table 1 - Study sample characteristics

\begin{tabular}{lc}
\hline Features & \\
\hline Age (years)* & $67.2 \pm 10.7$ \\
Gender, M/F (\%M) & $45 / 34(57)$ \\
Years of education* & $6.7 \pm 4.3$ \\
Disease duration* & $10.8 \pm 8.8$ \\
H\&Y stage, \% (n) & \\
$\mathbf{1}$ & $3.8(3)$ \\
$\mathbf{2}$ & $67.1(53)$ \\
$\mathbf{3}$ & $25.3(20)$ \\
$\mathbf{4}$ & $3.8(3)$ \\
MMSE score* & $27.3 \pm 2.7$ \\
MDS-UPDRS-Part I score $^{*}$ & $10.5 \pm 4.9$ \\
MDS-UPDRS-Part III score* $^{*}$ & $30.7 \pm 13.0$ \\
\hline
\end{tabular}

*Values are mean \pm standard deviation

H\&Y: Hoehn \& Yahr scale; MDS-UPDRS: Movement Disorders Society - Unified Parkinson's Disease Rating Scale; MMSE: Mini-Mental State Examination

\section{Reliability}

Our Portuguese version of the NMS-Quest exhibited an overall Cronbach's alpha of 0.862 and an ICC of 0.848 . For each domain, the alpha coefficients ranged from 0.183 to 0.902. Except for the cardiovascular domain (0.183), the digestive $(0.764)$, urinary $(0.840)$, apathy/attention/memory $(0.803)$, hallucinations/delusions $(0.885)$, depression/anxiety $(0.874)$, sexual function $(0.902)$, sleep disorders $(0.810)$ and miscellaneous symptoms $(0.730)$ were found to be internally consistent. The overall results for the ICC were equivalent, indicating satisfactory test-retest reliability.

\section{Validity}

Criterion validity analysis is shown in Table 3. All NMSQuest and related MDS-UPDRS-Part I domains were positively correlated with a significance value below 0.001 . The correlation coefficients ranged from 0.361 (miscellaneous symptoms) to 0.911 (hallucinations/delusions). Strong correlations were obtained between the digestive, urinary, apathy/attention/memory, depression/anxiety, cardiovascular

Table 2 - Descriptive analysis and psychometric indicators of NMS-Quest domains

\begin{tabular}{|c|c|c|c|c|c|c|c|}
\hline \multirow[b]{2}{*}{ NMS-Quest domain } & \multicolumn{5}{|c|}{ Acceptability } & \multicolumn{2}{|c|}{ Reliability } \\
\hline & $\%(n)$ & Range & Mean \pm SD & $\begin{array}{l}\text { Ceiling } \\
\text { effect, \% }\end{array}$ & $\begin{array}{l}\text { Floor } \\
\text { effect, \% }\end{array}$ & ICC & $\begin{array}{c}\text { Cronbach's } \\
\text { alpha }\end{array}$ \\
\hline Digestive & $82.3(65)$ & $0.0-7.0$ & $2.7 \pm 2.1$ & 1.3 & 17.7 & 0.741 & 0.764 \\
\hline Urinary & $72.2(57)$ & $0.0-2.0$ & $1.3 \pm 0.9$ & 59.5 & 27.8 & 0.839 & 0.840 \\
\hline Apathy/Attention/Memory & $74.7(59)$ & $0.0-3.0$ & $1.8 \pm 1.2$ & 43.0 & 25.3 & 0.798 & 0.803 \\
\hline Hallucinations/ Delusions & $27.8(22)$ & $0.0-2.0$ & $0.5 \pm 0.8$ & 20.3 & 72.2 & 0.885 & 0.885 \\
\hline Depression/Anxiety & $77.2(61)$ & $0.0-2.0$ & $1.5 \pm 0.8$ & 68.4 & 22.8 & 0.876 & 0.874 \\
\hline Sexual function & $62.0(49)$ & $0.0-2.0$ & $1.2 \pm 0.9$ & 53.2 & 38.0 & 0.902 & 0.902 \\
\hline Cardiovascular & $70.9(56)$ & $0.0-2.0$ & $0.9 \pm 0.7$ & 24.1 & 29.1 & 0.173 & 0.183 \\
\hline Sleep disorders & $81.0(64)$ & $0.0-5.0$ & $2.4 \pm 1.9$ & 21.5 & 19.0 & 0.804 & 0.810 \\
\hline Miscellany & $67.1(53)$ & $0.0-5.0$ & $1.6 \pm 1.6$ & 8.9 & 32.9 & 0.729 & 0.730 \\
\hline Total & - & $2.0-28.0$ & $13.7 \pm 6.3$ & 2.5 & 1.3 & 0.848 & 0.862 \\
\hline
\end{tabular}

ICC: intraclass correlation coefficient; SD: standard deviation 
Table 3 - Spearman correlation coefficients $(\rho)$ between NMS-Quest and MDS-UPDRS-Part I dimensions

\begin{tabular}{lll}
\hline \multicolumn{1}{c}{ NMS-Quest domain } & \multicolumn{1}{c}{ MDS-UPDRS-Part I domain } & \multicolumn{1}{c}{$\boldsymbol{\rho}^{*}$} \\
\hline Digestive & 1.11 Constipation problems & 0.767 \\
Urinary & 1.10 Urinary problems & 0.750 \\
Apathy/Attention/Memory & 1.1 Cognitive impairment & 0.911 \\
Hallucinations/Delusions & 1.5 Apathy & 0.752 \\
Depression/Anxiety & 1.2 Hallucinations, psychosis & \\
& 1.3 Depressed mood & 0.822 \\
Sexual function & 1.4 Anxious mood & \\
Cardiovascular & - & 0.784 \\
Sleep disorders & 1.12 Light headedness & 0.361 \\
& 1.7 Sleep problems & - \\
\hline
\end{tabular}

MDS-UPDRS: Movement Disorders Society Unified Parkinson's Disease Rating Scale

*All correlation coefficients were significant at $p<0.001$.

and sleep disorders domains and their corresponding MDSUPDRS-Part I dimensions. The frequency of hallucinations and/or delusions in the NMS-Quest presented a very strong correlation with the hallucinations/psychosis item in the MDS-UPDRS-Part I, while the frequency of miscellaneous symptoms was weakly correlated with pain and other sensations on the respective scales. There were no logical matches for the NMS-Quest sexual domain and the dopamine dysregulation syndrome in the MDS-UPDRS-Part I.

Construct validity was assessed comparing the NMSQuest domain scores with clinical indicators. The correlation matrix is shown in Table 4. The majority of the NMS-Quest dimensions presented a weak to moderate correlation with the MDS-UPDRS-Part I score, except for the sexual function domain. The domains concerning digestive, cardiovascular and sleep disorders exhibited very-weak to weak correlations with motor symptoms severity (MDS-UPDRSPart III score). Regarding cognitive function, the digestive, apathy/attention/memory, hallucinations/delusions, and depression/anxiety domains were negatively correlated with the MMSE score. However, the sexual function domain was positively correlated with a higher cognitive status.

Only domains concerning hallucinations/delusions and sleep disorders showed positive and very weak to weak correlations with disease duration. In terms of disease severity, the digestive, urinary, cardiovascular, sleep disorders and miscellany domains were positively correlated with the H\&Y stage. These correlations were considered very weak to weak.

\section{DISCUSSION}

Our study is the first European Portuguese translation and adaptation of the original English version of the NMSQuest that follows the international requirements for scale validation. Given their high prevalence and burden, we provide a reliable and valid screening instrument for non-motor symptoms in PD. The NMS-Quest differs from all other nonmotor symptoms questionnaires due to its self-completed and qualitative nature. It can be easily filled out by patients during or even before consultations. It allows us to overcome some of the time restraints during follow-up consultations and the patients' embarrassment in reporting their symptoms.

Table 4 - Spearman correlation coefficients $(\rho)$ between NMS-Quest dimensions and other applied scales or disease stages

\begin{tabular}{|c|c|c|c|c|c|}
\hline NMS-Quest domain & MDS-UPDRS-Part I & MDS-UPDRS-Part III & MMSE & Disease duration & H\&Y stage \\
\hline Digestive & $0.569^{*}$ & $0.492^{*}$ & $-0.244^{*}$ & 0.181 & $0.354^{*}$ \\
\hline Urinary & $0.352^{*}$ & 0.193 & -0.091 & -0.099 & $0.233^{*}$ \\
\hline Apathy/Attention/Memory & $0.613^{*}$ & 0.111 & $-0.223^{*}$ & 0.081 & 0.197 \\
\hline Hallucinations/Delusions & $0.344^{*}$ & 0.167 & $-0.241^{*}$ & $0.297^{*}$ & 0.116 \\
\hline Depression/Anxiety & $0.540^{*}$ & 0.220 & $-0.326^{*}$ & -0.057 & 0.211 \\
\hline Sexual function & 0.058 & -0.077 & $0.329^{*}$ & 0.102 & -0.007 \\
\hline Cardiovascular & $0.520^{*}$ & $0.263^{*}$ & -0.169 & 0.076 & $0.358^{*}$ \\
\hline Sleep disorders & $0.537^{*}$ & $0.373^{*}$ & -0.163 & $0.302^{*}$ & $0.441^{*}$ \\
\hline Miscellany & $0.462^{*}$ & 0.087 & -0.064 & 0.126 & $0.250^{*}$ \\
\hline
\end{tabular}

${ }^{*} p<0.05$

H\&Y: Hoehn \& Yahr scale; MDS-UPDRS: Movement Disorders Society - Unified Parkinson's Disease Rating Scale; MMSE: Mini-Mental State Examination 
The Portuguese NMS-Quest showed adequate psychometric properties in the fields of acceptability, reliability, and validity. The overall score did not show any ceiling and floor effects, although they were present in most of the domains that contained a small number of items due to the increased likelihood of scoring the highest and lowest possible on those items. The cardiovascular NMS-Quest domain did not reach acceptable internal consistency and test-retest reliability in our study. This domain is composed of one item screening for dizziness secondary to orthostatic hypotension and another regarding the frequency of falls. Although orthostatic hypotension may indeed prompt patients to fall, motor complications (postural instability, gait freezing, dyskinesias) have been established as major risk factors for falling, ${ }^{15-17}$ which may explain the low internal consistency coefficient obtained.

Other NMS-Quest domains such as gastrointestinal and miscellaneous symptoms showed only marginally acceptable internal consistency. The gastrointestinal domain includes one item concerning constipation while also screening for intestinal incontinence. Although both can be present at the same time, we found that obstipation was reported by $58.2 \%$ of patients and intestinal incontinence by $8.9 \%$, which is consistent with previous studies ${ }^{18,19}$ but reflected on a lower Cronbach's alpha coefficient. Only five patients reported these symptoms simultaneously and had a longer disease duration when compared with the overall sample (mean 17.2 years). Moreover, the miscellany domain is composed of items that cannot fit in any of the other categories. Therefore, it is expected that these symptoms are not consistently present among patients with PD.

Significant correlations between all NMS-Quest domains and the corresponding items on the MDS-UPDRSPart I were found. Hallucinations and/or delusions showed the strongest association with the matching item on our 'gold-standard' scale, but the miscellaneous cluster showed a weak correlation probably due to conceptual differences. The miscellany domain in the NMS-Quest comprises items testing for pain, weight changes, swelling, sweating and diplopia while the corresponding MDS-UPDRS-Part I item only mentions pain, tingling, and cramps.

Regarding construct validity, we were able to establish significant correlations between each NMS-Quest domain and disease-related variables (MDS-UPDRS-Part I, MDSUPDRS-Part III, MMSE, disease duration, and H\&Y stage). Digestive and cardiovascular symptoms presented the strongest correlations with disease severity, but not with disease duration, which is in line with Braak's pathological findings where the degeneration of the autonomic nervous system and lower brain stem precedes that of the cortex as the disease spreads. ${ }^{20}$ The severity of motor symptoms was mainly correlated with the presence of digestive symptoms. These symptoms may anticipate the motor manifestations of the disease, and particularly dysphagia, constipation, and fecal incontinence can be caused or worsened by gastrointestinal muscles dysmotility. ${ }^{21}$

Interestingly, sexual function was the only domain exhib- iting a positive correlation with the MMSE score, indicating that sexual performance was highly dependent on cognitive status. This effect has been reported in men, where decreased cognitive function was associated with less sexual interest and loss of libido. ${ }^{22}$

There is a lack of comparable data with other NMSQuest validation studies. To our knowledge, only the Italian translation and validation ${ }^{23}$ followed a similar methodology, but the differences in the grouping of the items prevented us from drawing direct comparisons. When compared with the original scale validation cohort, ${ }^{24}$ our patients had a higher disease duration (10.8 \pm 8.8 vs $6.4 \pm 4.3$ years), lower disease severity ( $2.3 \pm 0.6$ vs 2.5$)$ and were slightly younger $(67.2 \pm 10.7$ vs $68.1 \pm 10.3$ years old $)$. These facts could explain the epidemiological differences between the frequency of non-motor symptoms observed and that reported on the original scale validation and general studies. While meta-analyses show that urinary problems are the most prevalent among PD patients around the world, ${ }^{25}$ sleep/ fatigue, and cardiovascular symptoms were reported to be the most frequent in the Portuguese population. ${ }^{26}$

There are limitations to our study worth mentioning. First, our sample was also smaller compared to that of the original scale validation (79 vs 123 patients), but similar to other translations and validations..$^{23,27}$ The majority of the patients had mild to moderate stages of the disease, which may underestimate the reporting of symptoms typical of advanced stages (memory loss, apathy, depression, etc. $)^{28}$ and influence the generalizability of the results. Future studies concerning the applicability of the NMS-Quest in advanced stages of the disease are required. Also, our 'gold-standard' scale (MDS-UPDRS-Part I) does not include items enquiring for sexual dysfunction symptoms that could be used for the validity analysis of the sexual function domain of the NMS-Quest. Finally, the grouping of contrary or unrelated symptoms may have led to the low internal consistency and criterion validity observed in some domains, respectively.

\section{CONCLUSION}

The Portuguese version of the NMS-Quest is a useful screening tool for non-motor symptoms in PD patients that meets the validity and reliability requirements in the majority of its domains. Cardiovascular and gastrointestinal scores should be interpreted carefully. We recommend the routine use of NMS-Quest in the outpatient setting to help diagnose and treat identified symptoms.

\section{ACKNOWLEDGMENTS}

We thank Joana Lopes and Sónia Sacramento for their help during translation and patient recruitment.

\section{PROTECTION OF HUMANS AND ANIMALS}

The authors declare that the procedures were followed according to the regulations established by the Clinical Research and Ethics Committee and to the Helsinki Declaration of the World Medical Association. 


\section{DATA CONFIDENTIALITY}

The authors declare having followed the protocols in use at their working center regarding patients' data publication.

\section{CONFLICTS OF INTEREST}

The authors report no conflicts of interest.

\section{REFERENCES}

1. Kalia LV, Lang AE. Parkinson's disease. Lancet. 2015;386:896-912.

2. Zhang TM, Yu SY, Guo P, Du Y, Hu Y, Piao YS, et al. Nonmotor symptoms in patients with Parkinson disease: a cross-sectional observational study. Medicine. 2016;95:e5400.

3. Chaudhuri KR, Healy DG, Schapira AH. Non-motor symptoms of Parkinson's disease: diagnosis and management. Lancet Neurol. 2006;5:235-45.

4. Berganzo K, Tijero B, Gonzalez-Eizaguirre A, Somme J, Lezcano E, Gabilondo I, et al. Motor and non-motor symptoms of Parkinson's disease and their impact on quality of life and on different clinical subgroups. Neurologia. 2016;31:585-91.

5. McNeely ME, Duncan RP, Earhart GM. Impacts of dance on non-motor symptoms, participation, and quality of life in Parkinson disease and healthy older adults. Maturitas. 2015;82:336-41.

6. Estrada-Bellmann I, Camara-Lemarroy CR, Calderon-Hernandez HJ, Rocha-Anaya JJ, Villareal-Velazquez HJ. Non-motor symptoms and quality of life in patients with Parkinson's disease in Northeastern Mexico. Acta Neurol Belg. 2016;116:157-61.

7. Palmeri R, Lo Buono V, Bonanno L, Sorbera C, Cimino V, Bramanti P, et al. Potential predictors of quality of life in Parkinson's disease: sleep and mood disorders. J Clin Neurosci. 2019;70:113-7.

8. Bugalho P, Ladeira F, Barbosa R, Marto JP, Borbinha C, Salavisa M, et al. Motor and non-motor function predictors of mortality in Parkinson's disease. J Neural Transm. 2019;126:1409-15.

9. Shulman LM, Taback RL, Rabinstein AA, Weiner WJ. Non-recognition of depression and other non-motor symptoms in Parkinson's disease. Parkinsonism Relat Disord. 2002;8:193-7.

10. Storch A, Odin P, Trender-Gerhard I, Fuchs G, Reifschneider G, Chaudhuri KR, et al. Non-motor symptoms questionnaire and scale for Parkinson's disease. Cross-cultural adaptation into the German language. Nervenarzt. 2010;81:980-5.

11. Varney S, Lockhart I, Bakhshi L, Richards A, Ingham J, Klaeijsen E. Parkinson's disease: national clinical guideline for diagnosis and management in primary and secondary care. NICE Clinical Guidelines. 2011;1:10022.

12. Santana I, Duro D, Lemos R, Costa V, Pereira M, Simões MR, et al. Minimental state examination: avaliação dos novos dados normativos no rastreio e diagnóstico do défice cognitivo. Acta Med Port. 2016;29:2408.

13. Grimes DA, Hubacher D, Nanda K, Schulz KF, Moher D, Altman DG. The good clinical practice guideline: a bronze standard for clinical research. Lancet. 2005;366:172-4.

14. Terwee CB, Bot SD, de Boer MR, van der Windt DA, Knol DL, Dekker

\section{FUNDING SOURCES}

This research received no specific grant from any funding agency in the public, commercial, or not-for-profit sectors.

J, et al. Quality criteria were proposed for measurement properties of health status questionnaires. J Clin Epidemiol. 2007;60:34-42.

15. Farombi TH, Owolabi MO, Ogunniyi A. Falls and their associated risks in Parkinson's disease patients in Nigeria. J Mov Disord. 2016;9:160-5.

16. Wood BH, Bilclough JA, Bowron A, Walker RW. Incidence and prediction of falls in Parkinson's disease: a prospective multidisciplinary study. J Neurol Neurosurg Psychiatry. 2002;72:721-5.

17. Gray P, Hildebrand K. Fall risk factors in Parkinson's disease. J Neurosci Nurs. 2000;32:222-8.

18. Edwards LL, Pfeiffer RF, Quigley EM, Hofman R, Balluff M. Gastrointestinal symptoms in Parkinson's disease. Mov Disord. 1991;6:151-6.

19. Sakakibara R, Kishi M, Ogawa E, Tateno F, Uchiyama T, Yamamoto T, et al. Bladder, bowel, and sexual dysfunction in Parkinson's disease. Parkinsons Dis. 2011;2011: 924605.

20. Braak H, Tredici KD, Rüb U, de Vos RA, Jansen Steur EN, Braak E. Staging of brain pathology related to sporadic Parkinson's disease. Neurobiol Aging. 2003;24:197-211.

21. Cersosimo MG, Benarroch EE. Neural control of the gastrointestinal tract: implications for Parkinson disease. Mov Disord. 2008;23:1065-75.

22. Kummer A, Cardoso F, Teixeira AL. Loss of libido in Parkinson's disease. J Sex Med. 2009;6:1024-31.

23. Cova I, Di Battista ME, Vanacore N, Papi CP, Alampi G, Rubino A, et al. Adaptation and psychometric properties of the Italian version of the non-motor symptoms questionnaire for Parkinson's disease. Neurol Sci. 2017;38:673-8.

24. Chaudhuri KR, Martinez-Martin P, Schapira AH, Stocchi F, Sethi K, Odin $\mathrm{P}$, et al. International multicenter pilot study of the first comprehensive self-completed nonmotor symptoms questionnaire for Parkinson's disease: the NMSQuest study. Mov Disord. 2006;21:916-23.

25. Tagliati M, Chaudhuri K, Pagano G. Prevalence of non-motor symptoms in Parkinson's disease:a systematic review with meta-analysis. Neurology. 2014;82:P2.053.

26. Bugalho P, Lampreia T, Miguel R, Mendonça MD, Caetano A, Barbosa R. Non-motor symptoms in Portuguese Parkinson's sisease patients: correlation and impact on quality of life and activities of daily living. Sci Rep. 2016;6:1-9.

27. Rios Romenets S, Wolfson C, Galatas C, Pelletier A, Altman R, Wadup $\mathrm{L}$, et al. Validation of the non-motor symptoms questionnaire (NMSQuest). Parkinsonism Relat Disord. 2012;18:54-8.

28. Tanveer K, Attique I, Sadiq W, Ahmad A. Non-motor symptoms in patients with Parkinson's disease: a cross-sectional survey. Cureus. 2018;10:e3412. 